Review Article

\title{
Prevalence of Soy Allergies and Use of Genetically Modified Soy
}

\author{
Chandni Rathod, Nydia Sanchez, Masaru Teramoto*
}

Department of Health Sciences, College of Nursing and Health Professions, Drexel University, Philadelphia, USA

\section{Received Date: March 02, 2015 Accepted Date: March 31, 2015 Published Date: April 04, 2015}

Corresponding author: Teramoto, $\mathrm{M}$. Department of Health Sciences, College of Nursing and Health Professions, Drexel University, Philadelphia, USA. Tel: +1267-359-5718; Fax: +1-267-359-5722; E-mail: Masaru.Teramoto@drexel.edu

Citation: Teramoto, M. et al. Prevalence of Soy Allergies and Use of Genetically Modified Soy. (2015) J Food Nutr Sci 2(1): 55-57.

Keywords: Soy allergies; Soy sensitivities; Genetically modified soy; Children; Prevalence

\begin{abstract}
There is a growing trend of both genetically modified food consumption within the U.S. population and increasing food allergies among children in the U.S. This paper discusses whether a correlation exists between the number of children in the U.S. who have developed soy allergies and the increased use of genetically modified soy over time. Genetic modification and food allergies may be linked to each other, as certain proteins introduced to genetically modified food may lead to allergic or toxic reaction in some people. During the past 20 years, the use of genetically modified food has increased significantly. It can be assumed that children are experiencing more food allergies because their immune systems are still immature. They are being exposed to foods that may cause allergies, such as soy, at an earlier age because it is in staple foods, such as baby food, breads, baking mixes, crackers, breakfast cereals, canned broths, low fat peanut butter, and more. Soy allergies are many times outgrown in children, as determined through periodic skin prick tests. However, studying a possible correlation between soy allergies and increased use of genetically modified soy is important clinically, so that children can be accurately diagnosed and symptoms can be relieved as early as possible. Further research needs to be done to analyze whether the cross of genes from proteins introduced to genetically modified food creates a significant increase in soy allergies within children.
\end{abstract}

\section{Introduction}

Genetically modified food was introduced to the U.S. population largely after the Food and Drug Administration's (FDA's) Statement of Policy: Foods Derived from New Plant Varieties Act in $1992^{[1]}$. One of the first commercialized genetically modified products was a tomato created with recombinant bovine growth hormones in 1994, and many other genetically modified products became commercialized including corn, cotton, squash, and soy ${ }^{[1]}$. Genes from bacteria and viruses were used to modify the DNA of these crops $^{[1]}$. The FDA's policy does not demand that genetically modified food be labeled for commercialization if it is similar to the original product ${ }^{[2]}$. Labels are only required for specific reasons such as a different nutritional property of presence of an allergen ${ }^{[2]}$.

In the U.S., the total area of genetically modified crops in 2001 was 35.7 million ha, and that number has been increasing steadily ${ }^{[3]}$. Some of the most widely used genetically modified products are corn and soy ${ }^{[3]}$. Since the prevalence of genetically modified food increased during the last few decades, there have been concerns about increased food allergies and the production of toxic substances ${ }^{[4]}$.

This topic is important because of the wide range of genetically modified food in the U.S., specifically, the use of genetically modified soy, including soy substitutes for milk, soy protein in breads, cookies, crackers, breakfast cereals, canned broths, low fat peanut butter, and more ${ }^{[5]}$. It is also important because there is an increased prevalence of food allergies in children, and soy is one of the most widely used genetically modified crops ${ }^{[6]}$. One of the questions to be addressed is: Has there been a significant difference in the prevalence of soy allergies or sensitivities among children in the U.S. before and after the FDA's Statement of Policy, Foods Derived from New Plant Varieties Act in 1992, when the use of genetically modified soy increased? This paper discusses whether there is a correlation between the number of children in the U.S. who have developed soy allergies and the use of genetically modified soy.

\section{Review of Literature}

The process of genetically modifying crops occurs by removing genes from one organism and adding them to another ${ }^{[1]}$. This exchange of genes does not only have to be from other crops, for example, transferring a gene from the bacteria Bacillus thuringiensis has been shown to create crystal proteins that kill insects ${ }^{[1]}$. This alters the genetic makeup of the intended crop in ways that are beneficial for marketing the item, including better nutritional properties, tolerance to herbicides and pesticides, and increased shelf life ${ }^{[7]}$. In the U.S., genetically modified food was largely introduced to consumers after the FDA's Statement of Policy: Foods Derived from New Plant Varieties Act in $1992^{[7]}$. In 1993, recombinant growth hormones were approved by the FDA for use in crops ${ }^{[7]}$. The first case of genetically modified food available to the American consumers was a genetically modified tomato with recombinant growth hormones

Copy rights: (C2015 Teramoto, M. This is an Open access article distributed under the terms of Creative Commons Attribution 
in $1994^{[7]}$. This modification was used to increase the shelf- life on the tomato ${ }^{[7]}$. In 1996, a variety of other genetically modified crops were introduced to the market that were insect resistant and herbicide tolerant ${ }^{[8]}$. This group of crops included corn, cotton, rapeseed, and soybean ${ }^{[8]}$.

The FDA's 1992 act does not require genetically modified food to be labeled unless it is significantly different from the original product ${ }^{[1]}$. The FDA claims that genetically modified food is safe for consumers ${ }^{[1]}$. According to the FDA, requiring genetically modified food to be labeled as such would increase the cost and slow down the distribution process ${ }^{[1]}$. Since 1992, the use of genetically modified food has largely increase [3]. In the U.S., the total area of genetically modified crops in 2001 was 35.7 million ha, and that number has been steadily increasing ${ }^{[3]}$. In 2013 , an estimated $60-80 \%$ of processed food in the U.S. contained genetically modified crops as ingredients ${ }^{[1]}$. Many of these foods include genetically modified corn and soy ${ }^{[1]}$.

A food allergy causes immune- mediated response after exposure to certain food causing certain symptoms ${ }^{[9]}$. This response would not be apparent without the presence of the food ${ }^{[9]}$. Symptoms of food allergies include itching, hives, abdominal pain, nausea, swelling of certain body parts, and more ${ }^{[9]}$. Evidence has shown that food allergies or sensitivities are more common in children than in adults ${ }^{[9]}$. According to the 2007 National Health Interview Survey, the prevalence of food allergies in children in the U.S. was $4 \%$, while the prevalence of food allergies in the adult U.S. population was $2.5-3 \%{ }^{[9]}$. Current trends show that these numbers are increasing in the U.S. as well as in many other countries, especially among children ${ }^{[9]}$.

Some of the most common food allergies in children are for peanuts, egg whites, seafood, milk, and soy ${ }^{[9]}$. Approximately $0.4 \%$ of children are allergic to soy, but many times these soy allergies are outgrown as determined through periodic skin prick tests ${ }^{[10]}$. A research study including patients from John Hopkins Pediatric Allergy Clinic showed that about $50 \%$ of children with soy allergies outgrew it by age seven ${ }^{[10]}$. Even though many soy allergies are outgrown, it is important to diagnose children who suffer from soy allergies to relieve the symptoms. Symptoms of soy allergies include eczema, nausea, abdominal pain, vomiting, diarrhea, nasal congestion, and swelling ${ }^{[10]}$. Soy allergies are difficult in particular because so many processed food products contain soy, making avoidance challenging ${ }^{[10]}$.

There was a research study examining allergens from endogenous soybeans based off of allergen databases and peerreviewed publications ${ }^{[11]}$. This study evaluated 15 different possible soybean allergens, eight of which had enough clinical data to confirm as allergens ${ }^{[11]}$. The results of this study should be used to understand what the composition for new soybean varieties should be ${ }^{[11]}$. It is apparent that genetically modifying soy can get rid of allergens present within soy. Once allergens are identified, they can be removed from the soy by adding new genes or proteins. However, adding outside genes may introduce new proteins, allergens, and toxicities that were not present originally. It is important to understand what health benefits or risks genetically modified soy may have.

There is a growing trend of both genetically modified food consumption within the U.S. population and increasing food allergies among children in the U.S. Further research needs to be done to understand if there is a correlation and maybe a causation between these two factors. Although the current FDA's policy states that genetically modified food is safe and does not need to be labeled, there are some concerns regarding the safety of genetically modified food in response to food allergies ${ }^{[4]}$. The safety of genetically modified food should be further researched, especially since this genetic modification may soon go beyond only crops ${ }^{[1]}$.

It is assumed that children are experiencing more food allergies because their immune systems are still immature and because they are being exposed to foods that may cause allergies, such as soy, at an earlier age ${ }^{[1]}$. This is potentially harmful because soy is so prevalent in processed or staple foods including baby food ${ }^{[1]}$. Genetic modification and food allergies may be linked together, because certain proteins introduced to genetically modified food may lead to allergic or toxic reaction in some people ${ }^{[7]}$. For example, a gene was added to soy from a Brazilian nut for nutritional enhancement ${ }^{[1]}$. A study reported that people who experienced common nut allergies also showed an allergic reaction to the genetically modified soy due to this added gene ${ }^{[1]}$. Further research needs to be done to know whether this cross of genes creates a significant increase in soy allergies within children.

Genetically modified foods manipulate genes to produce new proteins, which can trigger reactions, often seen in soy ${ }^{[12]}$. Human bodies are not familiar with new proteins, or new genetically engineered nutritional supplements. Measurements by the World Health Organization (WHO) have been taken to ensure that proteins produced by foreign bacteria will not result in adverse reactions ${ }^{[12]}$. New proteins are being compared with a database of proteins known to cause allergens, and based off criteria provided by the WHO, the protein may or may not be released for consumption ${ }^{[12]}$. However, prior to the establishment of the WHO criteria, soybean was released, and testing for soybean has not been conducted ${ }^{[12]}$. With the insertion of genes during genetically modified crops, potential risks can increase for endogenous allergens of commonly allergenic food crops ${ }^{[13]}$.

It is important to pay attention to the food we are consuming and to ensure if they are causing bodies to reject the product resulting in alimentary allergies, synthesis of toxic agents or resistance to antibiotics ${ }^{[4]}$. These reactions can cause discomfort and safety concerns to the individual ${ }^{[14]}$. Children can result in severe reactions, such as atopic dermatitis, enterocolitis, and Immunoglobulin $\mathrm{E}$ (IgE)-mediated multisystem reactions ${ }^{[15]}$. Food allergies, especially soy allergies, should be monitored in children. Soy is one of the most commonly used genetically engineered products ${ }^{[15]}$. Soy allergy is a common allergy, which can be correlated to the heavy amounts of soy implemented in genetically modified food consumption ${ }^{[15]}$. However, soy allergies often tend to be linked to other allergies ${ }^{[15]}$. For example, 88 percent of children with soy allergies also have peanut allergies ${ }^{[15]}$. Evaluating these adverse effects may make it possible to link the type of genetically modified food that is causing these effects ${ }^{[4]}$. By targeting what is being rejected by our body, we can then manipulate genetically modified foods in an attempt to get rid of the problem ${ }^{[14]}$.

In human epigenetics, certain genetic information is methylated to either hide, or express a certain gene. Hypermethylation is to silence a gene, or trait, while demethylation expresses that gene ${ }^{[16]}$. This information is established during embryonic development; however, environmental factors, such 
as diet can alter these expressions ${ }^{[17]}$. If genetically engineered products can access what types of food can hypermethylate or demethylate, then perhaps people can grow out of allergies and other diseases by consuming specific genetically modified foods that code for those food allergies or diseases. More specifically, these dietary changes would greatly influence the epigenetic control in regulating early embryonic development ${ }^{[17]}$. Research shows that in-utero exposure to certain epigenetic diets may lead to reprogramming of primary epigenetic profiles ${ }^{[17]}$. A genetically modified specific diet for specific traits along with prenatal supplements may lead to the prevention of allergies or diseases [17].

\section{Discussion}

Approximately 0.3-0.4 percent of children are allergic to soy and will most likely outgrow that allergy by age 3 to $10^{[15]}$. It is important to ask why some children grow out of certain allergies, while others do not. Since food allergies have also been found to be the result of a missing enzyme, it is important for science to pay close attention to enzymes ${ }^{[9]}$. Approximately 28 known soy allergies have been linked with IgE binding ${ }^{[15]}$. Scientist can target these enzymes to include them in foods that children with allergies lack. It is important to follow through with this mystery to understand how the human body is responding to genetically modified food. Genetically modified food is still fairly new. Keeping up with adverse effects is crucial in ensuring public health. We have not always had or presented such high levels of allergies, especially in soy, which have been found to correlate. Only recently, are we seeing effects of genetically modified foods in human allergies. Outgrowing allergies as children can be the result of evolutionary effects and adapting to these newly introduced proteins and genes ${ }^{[15]}$. Further experiments need to be conducted to determine whether genetically modified food will become outgrown all together, or if some people will not be able to ever outgrow them.

The idea behind genetically engineered products is that they can be manipulated to modify genes and proteins in order to increase shelf life and increase nutritional value. Genetically modified food can have effects on how people react to such products after consumption. If genetically modified food can be manipulated, further research can explain the causes of these adverse effects and manipulate the genes to avoid these adverse effects. By understanding where food allergies come from, we can then target a specific gene. Some food allergies are the result of a missing enzyme in people. If genetically modified food can supply that enzyme, reported food allergies can be lowered.

\section{References}

1. Wohlers, A. E. Labeling of genetically modified food: closer to reality in the United States? (2013) Politics Life Sci 32(1): 73-84.

2. Levy, A. S., Derby B. M. Report on consumer focus groups on biotechnology. US Food and Drug Administration. Center for Food Safety and Applied Nutrition. Office of Support and Analysis 2000.

3. Nap, J. P., Metz, P. L., Escaler, M., et al. The release of genetically modified crops into the environment. Part I. Overview of current status and regulations. (2003) Plant J 33(1): 1-18.

4. Kramkowska, M., Grzelak, T., Czyżewska, K. Benefits and risks associated with genetically modified food products. (2013) Ann Agric Environ Med 20(3): 413-419.

5. Sicherer, S. H. Food allergies: a complete guide for eating when your life depends on it. (2013) Johns Hopkins University Press 31.

6. Sicherer, S. H., Munoz-Furlong, A., Sampson, H. A. Prevalence of peanut and tree nut allergy in the United States determined by means of random digit dial telephone survey: a 5-year follow-up study. (203) J Allergy Clin Immunol 112(6): 1203-1207.

7. Wohlers, A. E. Regulating genetically modified food policy trajectories, political culture, and risk perceptions in the U.S., Canada, and EU. (2010) Politics Life Sci 29(2): 17-39.

8. Zilberman, D., Kaplan, S., Kim, E., et al. Continents divided: understanding differences between Europe and North America in acceptance of GM crops. (2013) GM Crops Food 4(3): 202-208.

9. Turnbull, J. L., Adams, H. N., Gorard, D. A. Review article: the diagnosis and management of food allergy and food intolerances. (2015) Aliment Pharmacol Ther 41(1): 3-25.

10. Savage, J. H., Kaeding A. J., Matsui, E.C., et al. The natural history of soy allergy. (2010) J Allergy Clin Immunol 125(3): 683-686.

11. Ladics, G. S., Budziszewski, G. J., Herman, R. A., et al. Measurement of endogenous allergens in genetically modified soybeans-short communication. (2014) Regul Toxicol Pharmacol 70(1): 75-79.

12. Genetically engineered foods may cause rising food allergies-genetically engineered soybeans. (2007) Institute for Responsible Technology.

13. Goodman, R. E., Panda, R., Ariyarathna, H. Evaluation of endogenous allergens for the safety evaluation of genetically engineered food crops: review of potential risks, test methods, examples and relevance. (2013) J Agric Food Chem 61(35): 8317-8332.

14. Kuiper, H. A., Kleter, G. A., Noteborn, H. P., et al. Assessment of the food safety issues related to genetically modified foods. (2001) Plant J 27(6): 503-528.

15. Masilamani, M., Commins, S., Shreffler, W. Determinants of food allergy. (2012) Immunol Allergy Clin North Am 32(1): 11-33.

16. Messerschmidt, D. M., Knowles, B. B., Solter, D. DNA methylation dynamics during epigenetic reprogramming in the germline and preimplantation embryos. (2014) Genes Dev 28(8): 812-828.

17. Li, Y., Saldanha, S. N., Tollefsbol, T. O. Impact of epigenetic dietary compounds on transgenerational prevention of human diseases. (2014) AAPS J 16(1): 27-36.
Online ISSN: 2377-0619

Journal Title: International Journal Food and Nutritional Science Journal Short Name: Int J Nutr Sci
Ommega Online Publishers

E-mail: editor.foodscience@ommegaonline.com

Website: www.ommegaonline.com 